Article

\title{
Transesterification Kinetics of Waste Vegetable Oil in Supercritical Alcohols
}

\author{
Nawaraj Sanjel ${ }^{1}$, Jae Hoi Gu ${ }^{2}$ and Sea Cheon Oh ${ }^{1, *}$ \\ 1 Department of Environmental Engineering, Kongju National University, 1223-24 Cheonan-Daero, \\ Subuk, Cheonan, Chungnam 330-717, Korea; E-Mail: sanjelnawaraj@gmail.com \\ 2 Plant Engineering Center, Institute for Advanced Engineering, San 5, Woncheon-dong, Suwon, \\ Kyonggi 443-749, Korea; E-Mail: jaehoi@iae.re.kr \\ * Author to whom correspondence should be addressed; E-Mail: ohsec@kongju.ac.kr; \\ Tel.: +82-41-521-9423; Fax: +82-41-552-0380.
}

Received: 5 January 2014; in revised form: 11 March 2014 / Accepted: 17 March 2014 /

Published: 1 April 2014

\begin{abstract}
The kinetic analysis method using the non-isothermal technique was proposed to determine the kinetic parameters for the transesterification reaction of waste vegetable oil (WVO) in supercritical alcohols. To investigate the transesterification of WVO, experiments have been carried out with WVO and alcohols at three molar ratios of 1:6, 1:12 and 1:18 for both supercritical ethanol (SCE) and supercritical methanol (SCM) at temperatures between $210{ }^{\circ} \mathrm{C}$ and $350{ }^{\circ} \mathrm{C}$ in a $25 \mathrm{~mL}$ batch reactor. The products were analyzed by gas chromatography mass spectrometry (GC-MS). To verify the effectiveness of the proposed kinetic analysis method, the experimental values were compared with the values calculated using the kinetic parameters obtained from this work. It was found that the proposed kinetic analysis method gave reliable kinetic parameters for the transesterification of WVO in supercritical alcohols. It was also seen that SCM was a better solvent than SCE for the transesterification of WVO.
\end{abstract}

Keywords: non-isothermal; transesterification reaction; supercritical alcohols; kinetic analysis

\section{Introduction}

Due to the potential depletion of petroleum and environmental concerns about air pollution caused by the combustion of fossil fuels, alternative fuels have received much attention. Alternative fuels have 
the potential to solve the depletion problem of petroleum sources and concerns from air pollution and global warming to other environmental and sustainability issues [1]. Many researchers have studied biodiesel as a renewable energy resource [2-4]. Biodiesel, an alternative liquid fuel, is produced by transesterification reactions from various biological sources such as vegetable oil and animal fats $[5,6]$. Biodiesel has properties similar to those of diesel oil [7], and it can be used directly in diesel engines without modifications or after blending with petroleum products to achieve similar performance $[8,9]$. Further, biodiesel emits less $\mathrm{CO}, \mathrm{SO}_{x}$, and unburned hydrocarbons [3,4]. Transesterification is the chemical reaction between triglycerides and alcohol to produce monoesters. During transesterification, the long chains of triglycerides are converted to monoesters and glycerol [10-13]. Stoichiometrically, transesterification of $1 \mathrm{~mol}$ of triglyceride and $3 \mathrm{~mol}$ of alcohol produces $3 \mathrm{~mol}$ of fatty acid ester and 1 mol of glycerol. Diglycerides and monoglycerides are the intermediate products of the reaction process. Generally, there are two common methods for transesterification of biological source to biodiesel, one is the method using a catalyst termed as catalyzed transesterification method and the other is without the use of catalyst which is termed the supercritical fluid method.

In the catalyzed method, pretreatment is necessary for the oils with free fatty acid (FFA) levels of more than $4 \%$. For the pretreatment process, an acid process using sulfuric acid solution can be used in order to reduce the FFA to less than $2 \%$ and only then the transesterification can be done effectively [14-16]. Also, the purification process of the soapy product formed due to use of catalyst is another problem in the catalyzed method. However, these problems are not found in the supercritical fluid method. In addition, although the supercritical fluid method requires high temperature and pressure, the supercritical fluid reaction is very fast, i.e., at least hours (reaction time only) are needed in the catalyzed method whereas the supercritical fluid method takes only a few minutes for complete reaction [17]. In this work, kinetic analysis using the non-isothermal technique has been studied to determine the kinetic parameters for the transesterification reaction of waste vegetable oil (WVO) in supercritical methanol (SCM) and supercritical ethanol (SCE). Recently, many efforts have been devoted to develop new kinetic analysis methods for the transesterification reactions of vegetable oil in supercritical fluids [18-20]. Kusgiana and Saka [21] proposed the one step model and Song et al. [11] proposed the reaction rates to be the second order model. However, these kinetic analysis methods were based on the isothermal technique. In a previous work, the authors evaluated the kinetic analysis methods for wood and polymer degradation in supercritical fluids by using the non-isothermal technique [22-25]. It is well known that kinetic investigations are very important to get information for rationally designing reaction systems, but unfortunately, factors such as hard reaction conditions and difficulty of continuous operation, etc. tend to limit the kinetic study using the non-isothermal technique in the reactions in supercritical fluids. Therefore, the purpose of this work is to use the kinetic analysis method based on the non-isothermal technique for the transesterification reaction of WVO in supercritical alcohols. There is no intention in this work to describe the fundamental chemical mechanisms of the transesterification reaction of vegetable oil in supercritical alcohols or to analyze the product yields. Rather, this work is focused on the measurement of apparent kinetic parameters useful for the engineering design of chemical processes. 


\section{Experimental Section}

\subsection{Materials and Apparatus}

Waste soybean oil containing 3.15\% FFA was used as raw material in this work. The FFA content of the WVO was determined by titration with $0.1 \mathrm{M} \mathrm{KOH}$ solution using phenolphthalein as the indicator. As solvents, methanol of $99.5 \%$ purity manufactured by Ducksan Chemical Co. (Gyeongju, Korea), and ethanol of $99.9 \%$ purity produced by OCI Company Ltd. (Seoul, Korea) were used. Figure 1 shows the schematic diagram of the batch-type reactor manufactured by Parr Instrument Co. (Moline, IL, USA) with volume of $25 \mathrm{~mL}$. The permissible reactor conditions are $500{ }^{\circ} \mathrm{C}$ and $55 \mathrm{MPa}$. The temperature of the reactant was measured by a K-type thermocouple, whereas the pressure inside the vessel was monitored by a digital pressure gauge.

Figure 1. Schematic diagram of experimental apparatus.

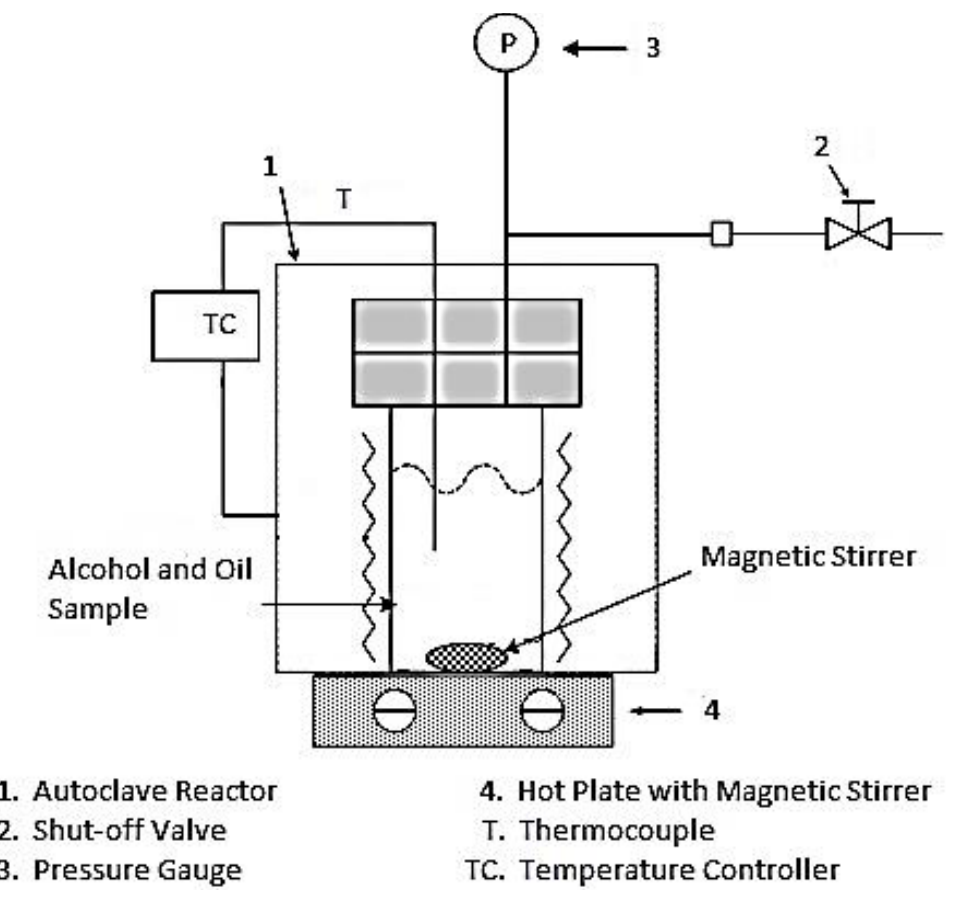

\subsection{Procedure}

The WVO was dried at a temperature of $110^{\circ} \mathrm{C}$ for $24 \mathrm{~h}$. The molar ratio of alcohol to soybean oil is one of the most important variables affecting the conversion yields of alkyl esters. The stoichiometry of the transesterification of soybean oil requires three molecules of alcohol to react with one molecule of soybean oil. In practice, an excess amount of alcohol is usually used to drive the reversible reaction to produce more ester. Therefore, experiments were carried out with WVO and alcohols at three different molar ratios of 1:6, 1:12 and 1:18 for both SCE and SCM at temperatures between $210{ }^{\circ} \mathrm{C}$ and $350{ }^{\circ} \mathrm{C}$ with intervals of $20^{\circ} \mathrm{C}$. At room temperature, the WVO with alcohol at definite molar ratios was charged into the autoclave reactor. The total amount of WVO and alcohols charged into the reactor was determined to ensure that supercritical pressure was reached. During the reaction, a magnetic stirrer was used for rigorous stirring at a rate of $500 \mathrm{rpm}$ so as to homogeneously mix the oil and alcohol solution. It was difficult to maintain a constant heating rate. In order to solve this problem, 
in this experiment, the set point of the temperature controller was set to a higher temperature than the required experimental temperature. When the reaction temperature got to the required experimental condition, the heating of the vessel was immediately stopped and the vessel was cooled in an ice bath to stop the reaction instantly. The products were analyzed by gas chromatography-mass spectrometer (Agilent GC-6890 with MSD-5975 detector, California, CA, USA). The area percentage method was used to estimate the amount of alkyl esters in the product. Table 1 shows the analysis conditions of gas chromatography mass spectrometry (GC-MS) used in this work.

Table 1. Operation conditions of gas chromatography mass spectrometry (GC-MS) analysis used in this work.

\begin{tabular}{cc}
\hline Item & Condition \\
\hline Column & DB-WAX $(30 \mathrm{~m} \times 250 \mu \mathrm{m}, 0.25 \mu \mathrm{m}$ thickness $)$ \\
Oven temperature & From $100^{\circ} \mathrm{C}(2 \mathrm{~min})$ to $200^{\circ} \mathrm{C}(5 \mathrm{~min})$ at $10^{\circ} \mathrm{C} / \mathrm{min} ;$ \\
He gas flow & From $230^{\circ} \mathrm{C}(5 \mathrm{~min})$ to $250^{\circ} \mathrm{C}(5 \mathrm{~min})$ at $10^{\circ} \mathrm{C} / \mathrm{min}$ \\
Injection volume & $1 \mathrm{~mL} / \mathrm{min}$ \\
Split mode & $1 \mu \mathrm{L}$ \\
Detector temp & $10: 1$ \\
Mass scan range (SIM mode) & $250^{\circ} \mathrm{C}$ \\
\end{tabular}

\section{Results and Discussion}

\subsection{Effect of Temperature, Molar Ratio and Alcohols on Conversion}

The conversion of WVO to alkyl esters carried out in SCE and SCM is shown in Figure 2. In this work, the experiments were performed at reaction temperatures of $210-350{ }^{\circ} \mathrm{C}$ and reaction pressures of 5.1-16.5 $\mathrm{MPa}$ and 6.2-17.5 $\mathrm{MPa}$ in SCE and SCM, respectively. The critical temperatures and pressures of ethanol and methanol are $T_{\mathrm{c}}=243.0{ }^{\circ} \mathrm{C}, 239.4{ }^{\circ} \mathrm{C}$ and $P_{\mathrm{c}}=6.4 \mathrm{Mpa}, 8.1 \mathrm{MPa}$, respectively. Therefore, for some experiments of less than $240{ }^{\circ} \mathrm{C}$, the transesterification reactions of WVO with alcohols took place in near critical fluids. The product yield of biodiesel in supercritical fluids was affected by reaction pressure [26]. However, it was impossible to perform kinetic experiments at constant pressure with the non-isothermal technique because the vapor pressure of alcohol increased with the reaction temperature; therefore, the effect of reaction pressure was not considered in this work.

From Figure 2, it was found that the conversion trends in SCE and SCM were similar, and the conversion increased with temperature. Also, maximum conversions were almost $99 \%$ for both SCE and SCM. In the case of SCM, the maximum conversion was reached at $290{ }^{\circ} \mathrm{C}$, whereas the maximum conversion in SCE was reached at $330^{\circ} \mathrm{C}$. In addition, it was shown that the conversion was increased with increased molar ratio of WVO to alcohols although the conversion differences between molar ratios of 1:6 and 1:12 can be negligible [3,4].

Figure 3 shows the comparison of conversion in SCE and SCM with WVO and alcohols at three molar ratios of 1:6, 1:12 and 1:18, respectively. It was found from Figure 3 that the conversions in SCM were higher than those in SCE. The reactivity of triglycerides with alcohol decreases with increasing alkyl chain length of the alcohol. This might be due to the longer chain alkyl group 
hindering the hydroxyl group in the alcohol from reacting with the triglycerides to form fatty acid alkyl esters [12]. Hence, the SCE reaction had lower conversion compared to the SCM reaction. Hoffmann and Contadi [27] also studied the hydrogen bonds in SCE and SCM. From their work, the enthalpies of hydrogen bonding of methanol and ethanol are $12.8 \mathrm{~kJ} / \mathrm{mol}$ and $16.8 \mathrm{~kJ} / \mathrm{mol}$, respectively, which shows the possibility that the transesterification reaction of WVO in SCM is easier than the reaction in SCE.

Figure 2. Conversion of waste vegetable oil (WVO) to alkyl esters in supercritical alcohols:

(a) supercritical ethanol (SCE); and (b) supercritical methanol (SCM).

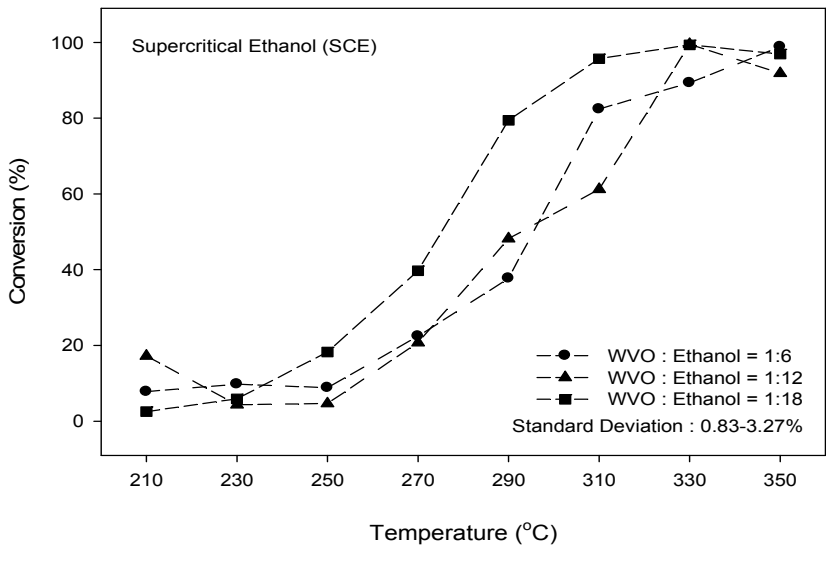

(a)

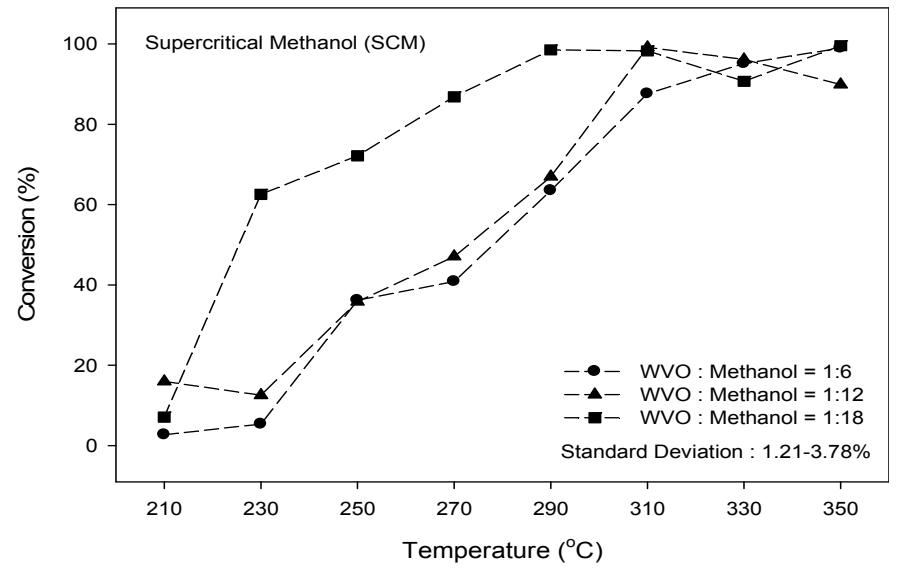

(b)

Figure 3. Comparison of conversion in SCE and SCM with WVO and alcohols at molar ratios of: (a) 1:6; (b) 1:12; and (c) 1:18.

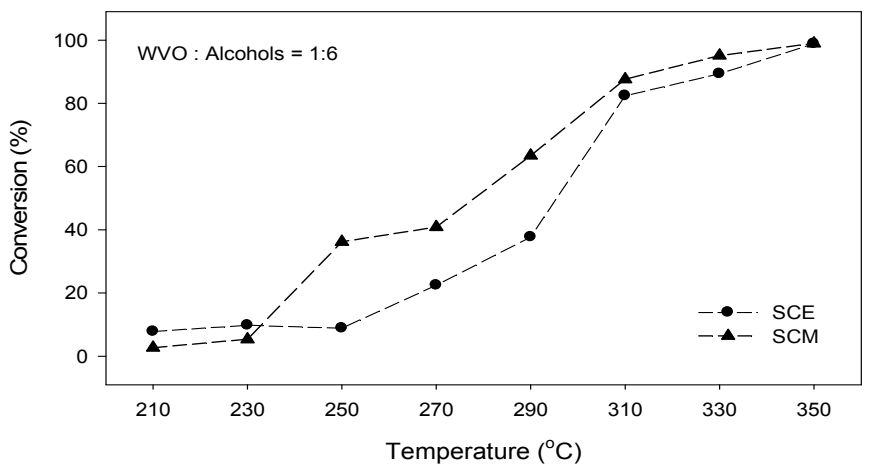

(a)

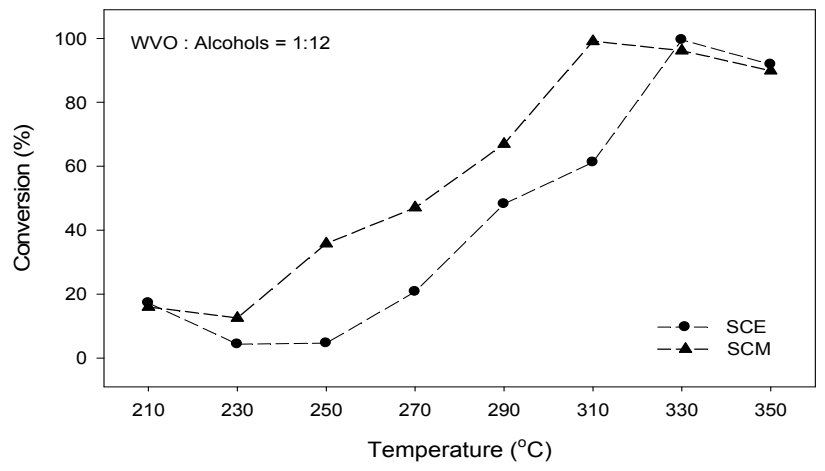

(b)

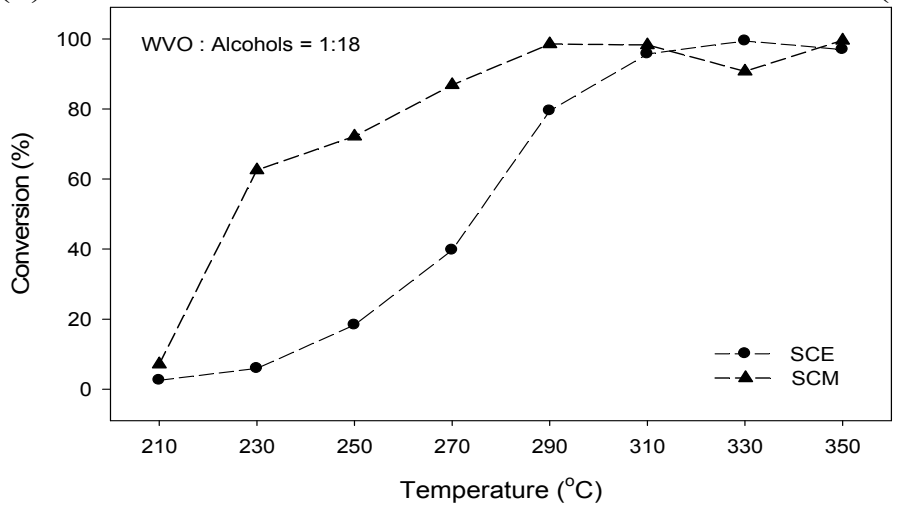

(c) 


\subsection{Kinetic Analysis}

Kusdiana and Saka [21] proposed a one step model for transesterification reactions in SCM as follows:

$$
\mathrm{TG}+3 \mathrm{MeOH} \rightarrow \mathrm{GL}+3 \mathrm{ME}
$$

where TG, $\mathrm{MeOH}, \mathrm{GL}$ and ME are triglycerides, methanol, glycerol and methyl ester, respectively. In this work, ethanol and methanol were used as solvents in the supercritical fluid reaction. Therefore, the reaction model of Equation (1) can be given as:

$$
\mathrm{TG}+3 \mathrm{AL} \rightarrow \mathrm{GL}+3 \mathrm{AE}
$$

where $\mathrm{AL}$ and $\mathrm{AE}$ denote alcohol and alkyl ester. The reaction rate of Equation (2) can be given by Equation (3):

$$
\text { Rate }=-\frac{\mathrm{d}(T G)}{\mathrm{d} t}
$$

where $T G$ refers to the content of WVO used in this work. In this supercritical alcohol method, three species were defined as alkyl esters, glycerol and unalkyl esterified compounds $\left(U_{\mathrm{AE}}\right)$ which include triglycerides, diglycerides, monoglycerides and unreacted FFA. Therefore, Equation (3) can be modified as [21]:

$$
\text { Rate }=-\frac{\mathrm{d}\left(U_{\mathrm{AE}}\right)}{\mathrm{d} t}
$$

In general, the overall rate equation of reaction is expressed in the Arrhenius form as:

$$
-\frac{\mathrm{d}\left(U_{\mathrm{AE}}\right)}{\mathrm{d} t}=A \exp \left(-\frac{E}{\mathrm{R} T}\right)\left(U_{\mathrm{AE}}\right)^{n}(A L)^{m}
$$

If the basic Equation (5) is taken and a heating rate $\beta=\mathrm{d} T / \mathrm{d} t$ is employed, it can be shown that:

$$
-\frac{\mathrm{d}\left(U_{\mathrm{AE}}\right)}{\left(U_{\mathrm{AE}}\right)^{n}}=\frac{A}{\beta} \exp \left(-\frac{E}{\mathrm{R} T}\right)(A L)^{m} \mathrm{~d} T
$$

where on integrating and introducing the initial condition of $U_{\mathrm{AE}}=1$ at $T=T_{0}$, the following expression is obtained as:

$$
\int_{1}^{U_{\mathrm{AE}}}-\frac{\mathrm{d}\left(U_{\mathrm{AE}}\right)}{\left(U_{\mathrm{AE}}\right)^{n}}=\frac{A}{\beta}(A L)^{m} \int_{T_{0}}^{T} \exp \left(-\frac{E}{\mathrm{R} T}\right) \mathrm{d} T
$$

After considering integral approximation [28], the following equations can be obtained:

$$
\begin{aligned}
& \frac{1-U_{\mathrm{AE}}^{1-n}}{1-n}=\frac{A \mathrm{R} T^{2}}{\beta E}(A L)^{m}\left(1-\frac{2 \mathrm{R} T}{E}\right) \exp \left(-\frac{E}{\mathrm{R} T}\right) \text { for } n \neq 1 \\
& -\ln \left(U_{\mathrm{AE}}\right)=\frac{A \mathrm{R} T^{2}}{\beta E}(A L)^{m}\left(1-\frac{2 \mathrm{R} T}{E}\right) \exp \left(-\frac{E}{\mathrm{R} T}\right) \text { for } n=1
\end{aligned}
$$


From logarithm of Equations (8) and (9), the following equations are derived, respectively:

$$
\begin{gathered}
\ln \left[\frac{1-U_{\mathrm{AE}}^{1-n}}{T^{2}(1-n)}\right]=F-\frac{E}{\mathrm{R} T} \text { for } n \neq 1 \\
\ln \left[\frac{-\ln \left(U_{\mathrm{AE}}\right)}{T^{2}}\right]=F-\frac{E}{\mathrm{R} T} \text { for } n=1 \\
\text { where } F=\ln \left[\frac{A \mathrm{R}}{\beta E}(A L)^{m}\left(1-\frac{2 \mathrm{R} T}{E}\right)\right]
\end{gathered}
$$

The plot of $\ln \left[\frac{1-U_{\mathrm{AE}}^{1-n}}{T^{2}(1-n)}\right]$ or $\ln \left[\frac{-\ln \left(U_{\mathrm{AE}}\right)}{T^{2}}\right]$ versus $\frac{1}{T}$ should give a straight line with the slope determining the activation energy $E$. While $F$ of Equation (12) can be expressed as:

$$
F=\ln \left[\frac{A R}{\beta E}\left(1-\frac{2 \mathrm{R} T}{E}\right)\right]+m \ln (A L)
$$

The value of $F$ can be obtained from y-axis intercept of the plot of Equations (10) and (11). For various concentrations of alcohols at given $\beta$, the plot of this value against $\ln (A L)$ yields a straight line with slope $m$.

Figures 4 and 5 show the application of the kinetic analysis method proposed in this work for SCE and SCM, respectively. For SCE, the heating rates were $5.7,4.8$ and $4.5^{\circ} \mathrm{C} / \mathrm{min}$ for molar ratios of 1:6, 1:12 and 1:18, whereas heating rates of $3.2,2.9$ and $4.8^{\circ} \mathrm{C} / \mathrm{min}$ for molar ratios of $1: 6,1: 12$ and 1:18 were used in the case of SCM, respectively. The best fit values for each experiment were determined employing the overall reaction order values, $n$ from 0.0 to 2.5 at interval of 0.25 . From Figures 2 and 3 , it was seen that after the transesterification reaction was complete, the conversion decreased with increasing temperature. This is because decomposition reactions take place at higher temperature due to the thermal degradation [21,29]. The kinetic analysis may be distorted by these results. Therefore, the conversion results increased with temperature were only used in the kinetic analysis of this work. The best overall fit values were obtained using the values of $n=0.75,0.75$ and 1.25 for molar ratios of 1:6, 1:12 and 1:18 in SCE, whereas in SCM the values of $n=1.75,0.5$ and 2.25 were obtained as the best fit values for molar ratios of 1:6,1:12 and 1:18, respectively.

The kinetic parameters obtained from this work are summarized in Table 2. The kinetic analysis method proposed in this work gave the apparent activation energies of $61.0-116.2 \mathrm{~kJ} / \mathrm{mol}$ and 64.9-180.8 kJ/mol for SCE and SCM, respectively. From this work, it was found that the apparent activation energy for SCE was lower than the value for SCM. There were variations in the calculated kinetic parameters depending on the molar ratio. The overall reaction orders, $m$ as shown in Table 2, were found to be 31.61 and 22.42 for SCE and SCM, respectively. These values are higher than typical reaction orders, and this is likely due to a mathematical complexity and the relation between parameters in the equation. 
Figure 4. Application of the kinetic analysis method for SCE with WVO and ethanol at molar ratios of: (a) 1:6; (b) 1:12; and (c) 1:18.

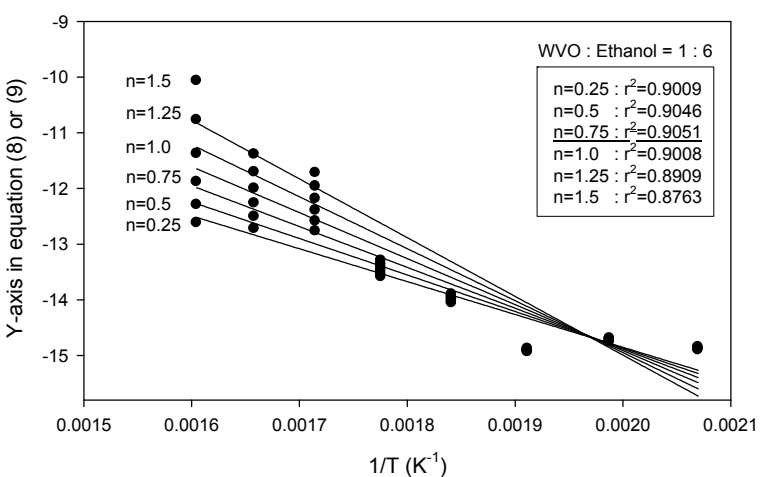

(a)

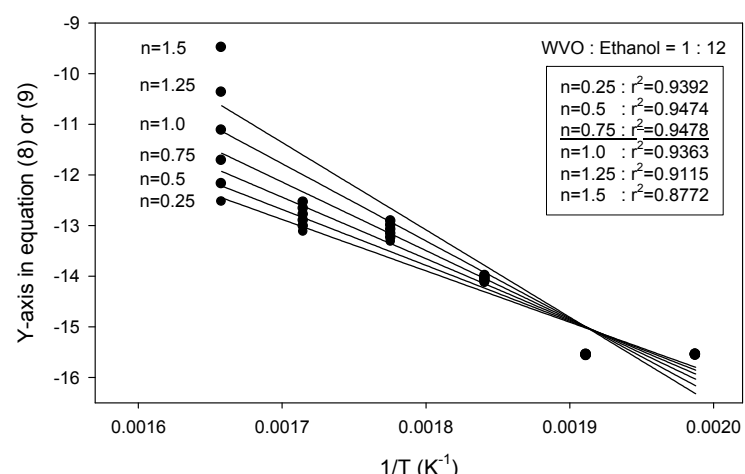

(b)

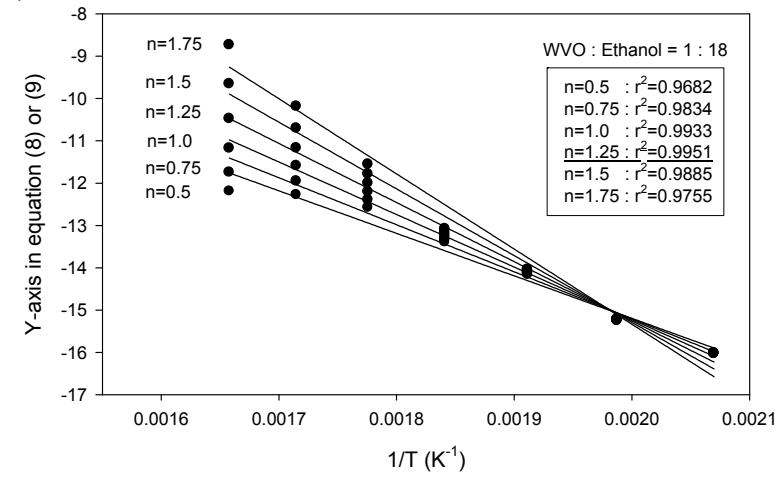

(c)

Figure 5. Application of the kinetic analysis method for SCM with WVO and methanol at molar ratios of: (a) 1:6; (b) 1:12; and (c) 1:18.

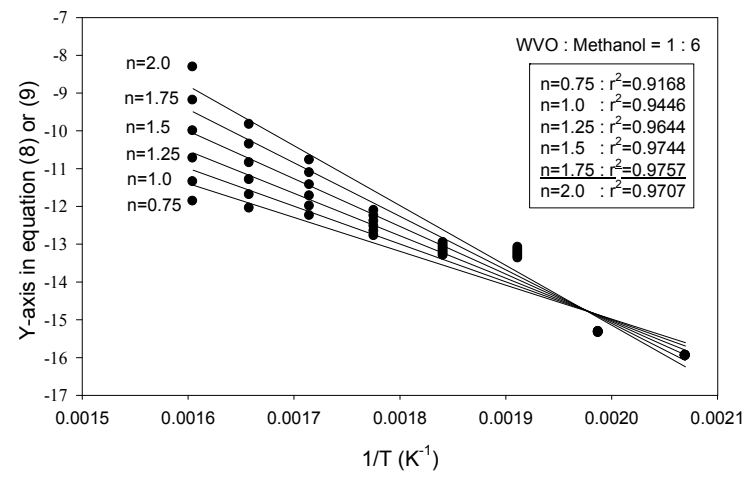

(a)

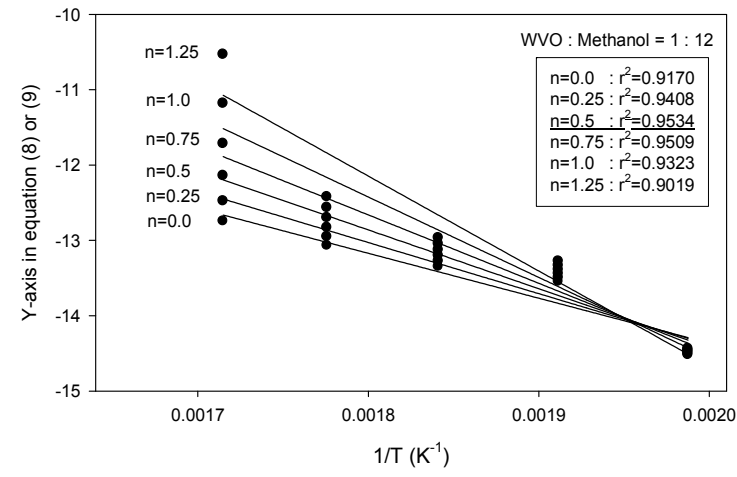

(b)

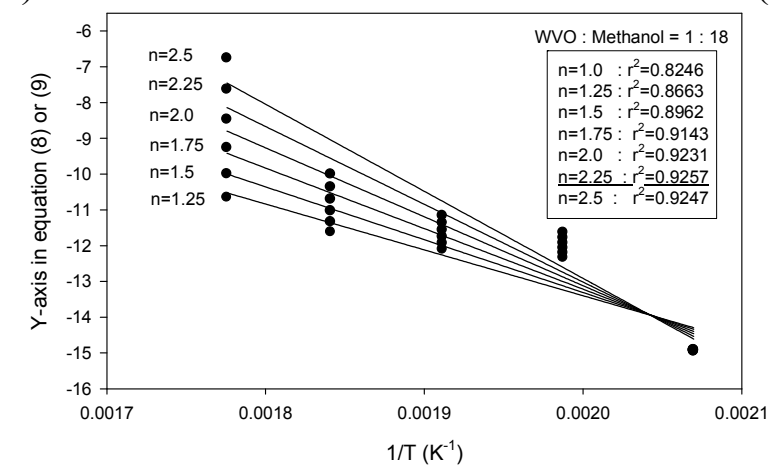

(c) 
Table 2. Summary of the kinetic parameters obtained from this work.

\begin{tabular}{|c|c|c|c|c|c|c|}
\hline Method & $\begin{array}{c}\text { Molar ratio } \\
\text { (WVO: alcohol) }\end{array}$ & $\begin{array}{l}\text { Reaction } \\
\operatorname{order}(n)\end{array}$ & $\begin{array}{c}\text { Activation energy } \\
(E, \mathrm{~kJ} / \mathrm{mol})\end{array}$ & $\begin{array}{c}\text { Heating rate } \\
\left(\beta,{ }^{\circ} \mathrm{C} / \mathrm{min}\right)\end{array}$ & $\begin{array}{l}\text { Reaction } \\
\operatorname{order}(m)\end{array}$ & $\begin{array}{l}\text { Pre-exponential } \\
\text { factor }\left(A, \min ^{-1}\right)\end{array}$ \\
\hline \multirow{3}{*}{ SCE } & $1: 6$ & 0.75 & 61.0 & 5.45 & \multirow{3}{*}{31.61} & $7.34 \times 10^{13}$ \\
\hline & $1: 12$ & 0.75 & 101.0 & 4.72 & & $1.05 \times 10^{14}$ \\
\hline & $1: 18$ & 1.25 & 116.2 & 4.42 & & $1.13 \times 10^{14}$ \\
\hline \multirow{3}{*}{ SCM } & $1: 6$ & 1.75 & 117.8 & 3.15 & \multirow{3}{*}{22.42} & $1.01 \times 10^{17}$ \\
\hline & $1: 12$ & 0.50 & 64.9 & 2.91 & & $5.14 \times 10^{16}$ \\
\hline & $1: 18$ & 2.25 & 180.8 & 4.74 & & $2.34 \times 10^{17}$ \\
\hline
\end{tabular}

The results obtained from this work for SCM and the results reported in the literature are summarized in Table 3. As shown in Table 3, there were tremendous variations in the calculated kinetic parameters depending upon the method used in the kinetic analysis. These observations clearly indicate the problems in the selection and utilization of analytical methods to study the transesterification reactions in supercritical fluid. The activation energy obtained from this work was higher than those from the literatures. Song et al. [11] assumed the reaction rates to correspond to a second order model with respect to both oil and methanol concentrations. In other literature the activation energies were also estimated by the zero order models for methanol concentration, and the first or zero order model with respect to vegetable oil concentration was used in the kinetic analysis. However, although the reaction order for methanol concentration in this work was higher than those of literatures, the overall reaction orders with respect to both oil and methanol concentration were estimated by the mathematical approach.

Table 3. Comparison of kinetic parameters in this work with literature.

\begin{tabular}{|c|c|c|c|}
\hline Reference & Reaction order (n) & Reaction order $(m)$ & Activation energy $(E, \mathrm{~kJ} / \mathrm{mol})$ \\
\hline \multirow{2}{*}{ Kusdiana and Saka [21] } & 1 & 0 & $38.4^{\mathrm{a}}$ \\
\hline & 1 & 0 & $47.1^{\mathrm{b}}$ \\
\hline \multirow{2}{*}{ He et al. [18] } & 1 & 0 & $11.2^{\mathrm{c}}$ \\
\hline & 1 & 0 & $56.0^{\mathrm{d}}$ \\
\hline Cheng et al. [19] & 1.5 & 0 & 28.9 \\
\hline Song et al. [11] & 0.96 & 1.05 & 105.3 \\
\hline \multirow{2}{*}{ Permsuwan et al. [20] } & 0 & 0 & $88.9^{\mathrm{e}}$ \\
\hline & 1 & 0 & $56.1^{\mathrm{f}}$ \\
\hline This work & $1.5^{\mathrm{g}}$ & 22.42 & $121.2^{\mathrm{g}}$ \\
\hline
\end{tabular}

To verify the effectiveness of the kinetic analysis method proposed in this work, Figure 6 shows the experimental values and the calculated values from Equations (10) and (11) by using the kinetic parameters of Table 2. From this figure, it was seen that the calculated values agreed well with the experimental values, and the kinetic analysis method used in this work gave reliable values of the kinetic parameters for the transesterification reactions of WVO in supercritical alcohols. 
Figure 6. Comparison of experimental results (symbol) and calculated values (line) for (a) SCE and (b) SCM.

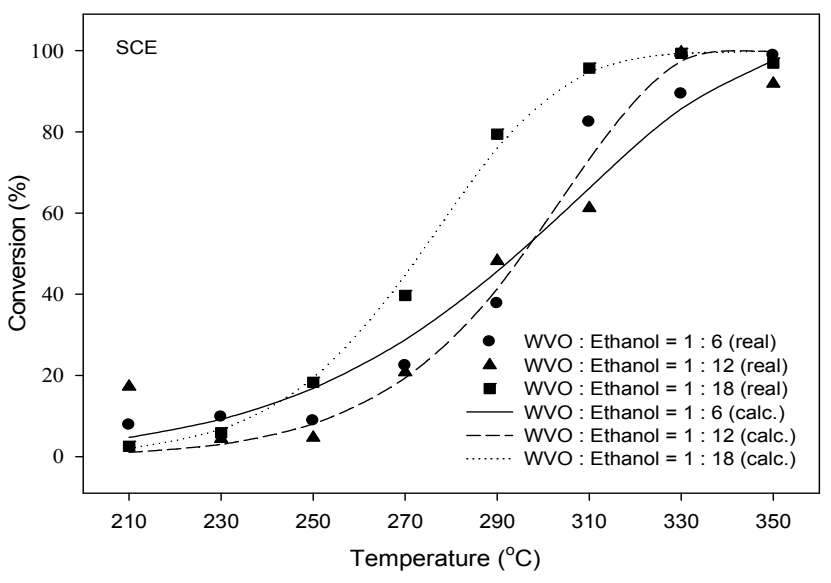

(a)

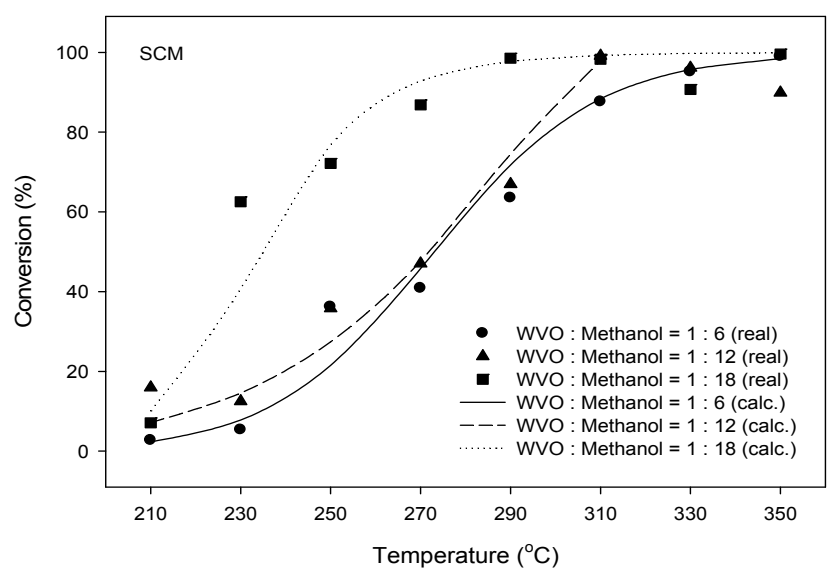

(b)

\section{Conclusions}

The kinetic analysis for the transesterification reaction of WVO was studied in supercritical alcohols. From this study, it was found that the conversion trends in SCE and SCM were similar, and the conversion increased with temperature. However, the conversions in SCM were higher than those of SCE. The kinetic analysis method used in this work gave apparent activation energies of 61.0-116.2 kJ/mol and 64.9-180.8 kJ/mol for SCE and SCM, respectively. It was also found that the apparent activation energy for SCE was lower than that for SCM. It was also seen that there were variations in the calculated kinetic parameters depending on the molar ratio. Also in this work, to verify the effectiveness of the kinetic analysis method proposed in this work, the experimental values were compared with the values calculated by using kinetic parameters obtained in this work. From the comparison of the experimental and calculated values, the kinetic analysis method proposed in this work gave reliable values of the kinetic parameters for the transesterification reactions of WVO in supercritical alcohols.

\section{Acknowledgments}

This work was supported by the Human Resources Development program (No. 20134030200230) and the New \& Renewable Energy Technology Development Program (No. 20123010100010) of the Korea Institute of Energy Technology Evaluation and Planning (KETEP) grant funded by the Korea government Ministry of Trade, Industry and Energy.

\section{Conflicts of Interest}

The authors declare no conflict of interest.

\section{References}

1. Demirbas, A. Biodiesel production from vegetable oils by supercritical methanol. J. Sci. Ind. Res. 2005, 64, 858-865. 
2. Campanelli, P.; Banchero, M.; Manna, L. Synthesis of biodiesel from edible, non-edible and waste cooking oils via supercritical methyl acetate transesterification. Fuel 2010, 89, 3675-3682.

3. Peng, B.; Shu, Q.; Wang, J.; Wang, G.; Wang, D.; Han, M. Biodiesel production from waste oil feedstocks by solid acid catalysis. Process Saf. Environ. Prot. 2008, 86, 441-447.

4. Demirbas, A. Biodiesel from waste cooking oil via base-catalytic and supercritical methanol transesterification. Energy Convers. Manag. 2009, 50, 923-927.

5. Alptekin, E.; Canakci, M. Optimization of transesterification for methyl ester production from chicken fat. Fuel 2011, 90, 2630-2638.

6. Shin, H.; Lee, S.; Ryu, J.; Bae, S. Biodiesel production from waste lard using supercritical methanol. J. Supercrit. Fluids 2012, 61, 134-138.

7. Encinar, J.M.; Gonzalez, J.F.; Rodríguez-Reinares, A. Biodiesel from used frying oil. Variables affecting the yields and characteristics of the biodiesel. Ind. Eng. Chem. Res. 2005, 44, 5491-5499.

8. Usta, N. Use of tobacco seed oil methyl ester in a turbocharged indirect injection diesel engine. Biomass Bioenergy 2005, 28, 77-86.

9. Demirbas, A. Biodiesel fuels from vegetable oils via catalytic and non-catalytic supercritical alcohol transesterifications and other methods: A survey. Energy Convers. Manag. 2003, 44, 2093-2109.

10. Gerpen, J.V. Biodiesel processing and production. Fuel Process. Technol. 2005, 86, 1097-1107.

11. Song, E.; Lim, J.; Lee, H.; Lee, Y. Transesterification of RBD palm oil using supercritical methanol. J. Supercrit. Fluids 2008, 44, 356-363.

12. Warabi, Y.; Kusdiana, D.; Saka, S. Reactivity of triglycerides and fatty acids of rapeseed oil in supercritical alcohols. Bioresour. Technol. 2004, 91, 283-287.

13. Köckritz, A.; Martin, A. Oxidation of unsaturated fatty acid derivatives and vegetable oils. Eur. J. Lipid Sci. Technol. 2008, 110, 812-824.

14. Ramadhas, A.S.; Jayaraj, S.; Muraleedharan, C. Biodiesel production from high FFA rubber seed oil. Fuel 2005, 84, 335-340.

15. Alptekin, E.; Canakci, M. Optimization of pretreatment reaction for methyl ester production from chicken fat. Fuel 2010, 89, 4035-4039.

16. Farag, H.A.; El-Maghraby, A.; Taha, N.A. Optimization of factors affecting esterification of mixed oil with high percentage of free fatty acid. Fuel Process. Technol. 2011, 92, 507-510.

17. Saka, S.; Kusdiana, D. Biodiesel fuel from rapeseed oil as prepared in supercritical methanol. Fuel 2001, 80, 225-231.

18. He, H.; Sun, S.; Wang, T.; Zhu, S. Transesterification kinetics of soybean oil for production of biodiesel in supercritical methanol. J. Am. Oil Chem. Soc. 2007, 84, 399-404.

19. Cheng, J.; Li, Y.; He, S.; Shen, W.; Liu, Y.; Song, Y. Reaction kinetics of transesterification between vegetable oil and methanol under supercritical conditions. Energy Sources Part A 2008, 30, 681-688.

20. Permsuwan, A.; Tippayawong, N.; Kiatsiriroat, T.; Thararux, C.; Wangkarn, S. Reaction kinetics of transesterification between palm oil and methanol under subcritical conditions. Energy Sci. Technol. 2011, 2, 35-42.

21. Kusdiana, D.; Saka, S. Kinetics of transesterification in rapeseed oil to biodiesel fuel as treated in supercritical methanol. Fuel 2001, 80, 693-698. 
22. Oh, S.C.; Kwak, H.; Baw, S.-Y. A kinetic analysis of polymer degradation in supercritical fluid. J. Chem. Eng. Jpn. 2006, 39, 1004-1009.

23. Oh, S.C.; Han, D.I.; Kwak, H.; Bae, S.-Y.; Lee, K.-H. Kinetics of the degradation of polystyrene in supercritical acetone. Polym. Degrad. Stab. 2007, 92, 1622-1625.

24. Poudel, J.; Oh, S.C. A kinetic analysis of wood degradation in supercritical alcohols. Ind. Eng. Chem. Res. 2012, 51, 4509-4514.

25. Poudel, J.; Oh, S.C. Degradation characteristics of wood using supercritical alcohols. Energies 2012, 5, 5038-5052.

26. Goembira, F.; Saka, S. Optimization of biodiesel production by supercritical methyl acetate. Bioresour. Technol. 2013, 131, 47-52.

27. Hoffmann, M.M.; Conradi, M.S. Are there hydrogen bonds in supercritical methanol and ethanol? J. Phys. Chem. B 1998, 102, 263-271.

28. Coats, A.; Redfern, J. Kinetic parameters from thermogravimetric data. Nature 1964, 201, 68-69.

29. Ilham, Z.; Saka, S. Two-step supercritical dimethyl carbonate method for biodiesel production from Jatropha curcas oil. Bioresour. Technol. 2010, 101, 2735-2740.

(C) 2014 by the authors; licensee MDPI, Basel, Switzerland. This article is an open access article distributed under the terms and conditions of the Creative Commons Attribution license (http://creativecommons.org/licenses/by/3.0/). 